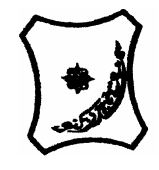

Bayero Journal of Pure and Applied Sciences, 2(1):122 - 124

Received: October, 2008

Accepted: May, 2009

\title{
ISOLATION AND IDENTIFICATION OF POSTHARVEST SPOILAGE FUNGI ASSOCIATED WITH SWEET ORANGES (CITRUS SINENSIS) TRADED IN KANO METROPOLIS
}

\author{
*Bukar, A., Mukhtar, M.D. and Adamu, S. \\ Department of Biological Sciences, Bayero University, P.M.B. 3011, Kano \\ *Correspondence author: al_amsak2004@yahoo.com
}

\begin{abstract}
Mycological studies on fungi in apparently diseased sweet oranges (Citrus sinensis) sampled from retailers at Na'ibawa Yan Lemu market in Kano Metropolis was carried out between August and September 2006. The samples were surface sterilized using $85 \%$ ethanol and homogenates were cultured on potato Dextrose Agar and incubated aerobically at room temperature for 7 days at $30^{\circ} \mathrm{C}$. Pure cultures of the resulting fungal colonies were obtained from the subcultures of the primary plates. These were identified morphologically and microscopically. The investigation revealed that up to $90 \%$ of the samples were infected with one or more fungal species. The most predominant pathogenic fungus isolated from the samples was, Aspergillus sp (32.5\%); others include Mucor sp. (25\%), Penicillium sp (15\%), Rhizopus sp (15\%), Fusarium sp, (7.5\%), and Alternaria sp. (5\%). Proper handling from the farm as well as during storage and the avoidance of mixing of diseased ones with the healthy ones were identified as important factors in preventing loss. The use of suitable chemical treatment of the orange is also recommended as means of reducing economic loss due to fungal pathogens.
\end{abstract}

Key words: Mycological studies, Fungal colonies, Sweet orange, Kano

INTRODUCTION

Microorganisms are associated, in a variety of ways with all the food we eat. They may influence the quality availability, and quantity of our food. Naturally occurring foods such as fruits and vegetables normally contain some microorganisms and may be contaminated with additional organisms during handling (Lund, 1971). Food can serve as a medium for the growth of microorganisms and as a result, transmit diseases. Other microorganisms, if allowed to grow in certain food products, produce toxic substances that result in food poisoning when ingested (Pelczar et al., 1993). Different disease problems arise when crops are harvested, because seed, fruit or other storage organs are essentially dormant structures and their cells are physiologically unlike those of growing plant (Daveport, 1978).

Citrus species probably originated in northeastern India in Burma and in the adjoining areas. Early in the spread of citrus, some species crossed into China where the sweet orange, the mandarins and kumquat developed (Hill, 1952; Abayomi, 2004). The lemons, the limes and the grapefruit appear to have developed and spread from India to the Mediterranean region. The ripened fruits are infected easily while the green ones show instance to infection due to the following reasons: green fruits don't meet the nutritional requirements of the fungus; the enzyme potential necessary for invading green fruits is greater than for ripe ones and is temporarily beyond the capability of the fungus; and some toxins present in the green fruits disappear or become inactive in the ripe ones (Mehrota, 2001).
The principle of spread of fungal infection in fruits supports that a single infected orange can be the source of infection to other oranges during storage and on transit (Jay, 2003). Soil-infesting fungi and bacteria that cause loss of fleshy tissue typically infect plants at the time of or just before harvesting. Infection may occur, however, during post harvest handling or storage. Common air molds such as Penicillium species may gain entry into the susceptible tissue and cause loss during packaging (Ronald, 1988). It is in view of this, that this research work was set up to identify fungi associated with sweet oranges sold in Kano metropolis

\section{MATERIALS AND METHODS}

\section{Sampling Site}

The sampling site was the Na'ibawa yan Lemo market, which is located along Zaria road in Tarauni local government of Kano state. It is a major market and depot for orange in Kano State. The oranges were mainly brought to the market from states such as Benue, Enugu, Kogi, Edo, Anambra, Ogun, Oyo and Ondo.

\section{Sample Collection}

A total of 40 samples in batches of 10 were randomly selected from different locations designated A-J in the market. At each point, one diseased orange was collected at a time. This was done for four different lots of the oranges brought into the market at intervals of several days. Spoiled or diseased oranges were identified by physical examination using the method of Balali et al. (1995). 
Various types of spoiled oranges were selected, including those that were mechanically wounded or bruised, with purplish to dark brown rot as well as those with black lesions on them. Healthy ones were also bought for use as controls.

\section{Preparation of samples}

The method of Balali et al. (1995) was adopted. The samples which are apparently diseased were cut from the advancing edges of lesion with a sterilized knife. The cut portion of the lesion was disinfected with ethanol of $85 \%$ concentration for 2 minutes. These were then rinsed in three different changes of distilled water. Each portion was then homogenized using a sterile glass rod and a test tube in $10 \mathrm{ml}$ of the homogenate $(1 \mathrm{~g}+9 \mathrm{ml})\left(10^{1}\right)$ was made and serially diluted down to $10^{-4}$

\section{Isolation of the Fungi}

Plates of already prepared Potato Dextrose Agar (PDA) containing Chloramphenicol $(30 \mathrm{mg} / \mathrm{l})$ to prevent the growth of bacteria were inoculated with $0.1 \mathrm{ml}$ aliquots of the serially diluted samples and incubated at ambient room temperature $\left(25-30^{\circ} \mathrm{C}\right)$ for 7 days. After 7 days, growth of fungal colonies on the agar were counted and recorded in colony forming unit per milliliter $(\mathrm{cfu} / \mathrm{ml})$. The same operation was repeated for the apparently healthy ones, which served as controls.

\section{Pathogenicity Test}

Healthy oranges were surface disinfected and three $2 \mathrm{~mm}$ holes were made with a flamed cooled wire loop. Scrapings of lesions of the diseased oranges were inoculated into the holes. Both inoculated and uninoculated oranges were incubated separately in plastic containers for 7 - 14days at ambient temperature $\left(25-30^{\circ} \mathrm{C}\right)$. After 7 - 14days, inoculated and uninoculated oranges were observed for growth of fungal colonies, which were matched with the colonies used as source of inoculum.

Identification of isolated fungi

The identification of isolated fungi was done according to the method of Fawole and Oso (1995). A drop of Lactophenol cotton blue stain was placed on a clean slide and with the aid of a mounted needle, a small portion of the mycelium from the fungal cultures was removed and placed in the drop of the stain. The mycelium was spread very well on the slide with the aid of two mounted needles. A cover slip was gently lowered on it, and excess liquid was wiped by putting the slide between two folds of filter paper and applying a gentle pressure around the cover slip. The slide was then examined under the microscope

The observation was done at low and high power objectives (XI0 and X40) of the microscope (Olympus model). Morphological characteristics of the fungi such as type of hyphae (whether septate or nonseptate), asexual reproductive structure (whether borne sporangia or conidia, in chain or single) were observed and recorded.

\section{RESULT}

Table 1 shows the number of samples collected from ten (10) sampling points (A - J). It also shows the mean viable count (cfu/ml) as well as the total samples obtained and the total samples infected. The result revealed that sampling points $A, B, C, D, E, H$ and $J$ had $4(100 \%)$ of the samples infected, while $F$, G had $3(75 \%)$ infected and sample I with the least number infected of $2(50 \%)$ and the mean fungal count ranged between $5.25 \times 10^{1}$ and $6.75 \times$ $10^{2} \mathrm{cfu} / \mathrm{ml}$ respectively. The frequency of occurrence of each fungal isolate is shown in Table 2. Aspergillus sp had the highest occurrence of $32.5 \%$, followed by Mucor sp (25\%), Penicillium sp and Rhizopus sp (15\%), Fusarium sp. (7.5\%), with Alternaria sp having the least occurrence of $5 \%$. Table 3 shows that all the fungal isolates were able to infect the healthy oranges with the exception of Alternaria spp, which was not able grow and produce disease condition on the inoculated healthy oranges.

Table 1: samples of apparently diseased oranges and the mean viable fungal count of isolates from Na'ibawa Yan Lemo Market, Kano

\begin{tabular}{lcccc}
\hline Sampling points & $\begin{array}{c}\text { Total samples } \\
\text { obtained }\end{array}$ & $\begin{array}{c}\text { Total samples } \\
\text { infected }\end{array}$ & \% samples infected & $\begin{array}{c}\text { Mean viable count } \\
\text { (cfu/ml) }\end{array}$ \\
\hline A & 4 & 4 & 100 & $2.00 \times 10^{2}$ \\
B & 4 & 4 & 100 & $1.20 \times 10^{2}$ \\
C & 4 & 4 & 100 & $2.47 \times 10^{2}$ \\
D & 4 & 4 & 100 & $1.05 \times 10^{2}$ \\
E & 4 & 4 & 100 & $2.02 \times 10^{2}$ \\
F & 4 & 3 & 75 & $1.80 \times 10^{2}$ \\
G & 4 & 3 & 75 & $6.75 \times 10^{2}$ \\
H & 4 & 4 & 100 & $2.65 \times 10^{2}$ \\
I & 4 & 2 & 50 & $5.25 \times 10^{1}$ \\
J & 4 & 4 & 100 & $1.37 \times 10^{2}$ \\
\hline Total & $\mathbf{4 0}$ & $\mathbf{3 6}$ & $\mathbf{9 0}$ & \\
\hline
\end{tabular}

Table 2: Frequency of occurrence of various fungal isolates in diseased oranges

\begin{tabular}{lll}
\hline S/N & Organisms identified & Frequency (\%) \\
\hline 1 & Aspergillus sp & 32.5 \\
2 & Mucor sp & 25.0 \\
3 & Penicillium sp & 15.0 \\
4 & Rhizopus sp & 15.0 \\
5 & Fusarium sp & 7.5 \\
6 & Alternaria sp & 5.0 \\
\hline
\end{tabular}


Bajopas Volume 2 Number 1 June, 2009

Table 3: Pathogenicity test on fresh/apparently healthy oranges

\begin{tabular}{cccccc}
\hline Aspergillus & Penicillium & Mucor & Rhizopus & Fusarium & Alternaria \\
\hline+ & + & + & - & + & - \\
+ & + & + & + & + & - \\
\hline
\end{tabular}

Key: $+=$ Isolates grow with a similar growth characteristic features to the original diseased samples

- = Isolates not able to grow on the sample

\section{DISCUSSION}

Na'ibawa yan Lemo Market in Kano served as the main depot where the major fruit dealers and suppliers sell to petty traders who in turn penetrate the metropolitan Kano and other local markets throughout the state and its neighbouhoods. The oranges were sourced from areas like Benue, Enugu, Kogi, Edo, Anambra, Ogun, Oyo and Ondo states.

The diseased oranges sampled from Na'ibawa yan lemo market in Kano were found to be massively infected with six genera of fungi namely Aspergillus sp. Penicillium sp, Mucor sp, Rhizopus sp, Fusarium sp. and Alternaria sp. Different spoilage types were noticed on reinfection of healthy oranges with pure isolated species of the pathogens. Some however, did not cause spoilage on re-infection. This could be due their inability of independent growth and survival on the orange and might be dependent on the breakdown product of other spoilage organisms or conditions for survival.

Aspergillus sp, Penicillium sp, Mucor sp, Rhizopus sp, and Fusarium sp, were able to cause spoilage on re-infection, Aspergillus sp, had about $20 \%$ occurrence rate on re-infection, as well as Penicillium, Mucor sp. and Rhizopus sp. Fusarium had about $10 \%$ on re-infection while Alternaria sp showed no growth. The occurrence of these organisms may be attributed to their ability to produce resistant spores, as reported by Faweette and Lee, (1926) that spores of Aspergillus are more resistant to high temperature. And in conjunction to this, Aspergillus species have been implicated in the spoilage of fruits and vegetables in Nigeria (Uzuegbu and Emiforiye, 1984). Fusarium is known to be moisture loving and tends to occur in fruits with relatively high moisture content, such as oranges. Contrary to this work, Uzuegbu and Emifoniye (1984) in their work of post harvest fungal spoilage of some Nigerian fruits and vegetables isolated Alternaria in $40 \%$ of the total samples used,

\section{REFERENCES}

Abayomi, A.O. (2004): General information about Citrus production in Nigeria. National Horticultural Research Institute Sem Press, Ibadan. P.4.

Balali, G. N., S. M. Scott, E.S. Whisson, D.L. and Wicks, T.J. (1995): Anastomosis group and pathogenicity of isolate of Rhizoctonia solari potato crop in South Australia. 3rd ed.

Daveport, M. (1978): Fruit Spoilage by some selected molds. Phytolog. Rev. 13:8

Fawole, M.O. and Oso, B.A. (1995): Laboratory Manual of Microbiology. $1^{\text {st }}$ Edition. Spectrum Books Ltd, Ibadan, Nigeria Pp. $34-35$.

Hill, F.A. (1952): Economic Botany. 2nd ed. Mc Graw Hill Book Company, United Kingdom. Pp. 218 - 287.
Alternaria (5\%) was isolated in this work. As outlined by these two workers, Uzuegbu and Emifoniye (1984), differences in storage conditions and varieties of these products in the different areas where they are produced may account for the variation in the isolates detected by different workers. They went further and said that different isolates observed may be due to varied geographical location where the fruits are grown and hence variation of the microflora of those locations.

The presence of the fungi or their resistant spores is most likely to have originated from the farms where the fruits were harvested and some from the stores due to horizontal contamination by the already spoilt fruits as Jay (2003) observed that most spoilage organisms may be present on fruits and vegetables from the farm, during harvest operations, and this may result in post harvest contamination and spoilage of these fruits and vegetables. The present and subsequent spoilage due to these fungi, if not checked could lead to serious economic loss and possible health hazards when these fruits are consumed.

\section{CONCLUSION}

Conclusively, the results of the present study have revealed the spoiled oranges were mainly contaminated with Aspergillus $s p$, Pencilium $s p$, and least contaminated with Alternaria. Some oranges were observed to have been contaminated with more than one fungal organism. Presence of these fungi on oranges, most especially Aspergillus sp poses a serious threat to health of consumers as the organism could produce mycotoxins, which are lethal when consumed. Most of the fungi isolated were observed to be able to reinfect healthy oranges within short time, which poses a serious economic threat to sellers of oranges in Yan lemo market.

Jay, J.M. (2003): Microbial Spoilage of Food. Modern Food Microbiology. $4^{\text {th }}$ ed. Chapman and Hall Inc. New York. Pp. $187-195$.

Lund, D.M. (1971): Bacterial spoilage of vegetable and certain fruits. J. Applied Bacteriology, 34:9- 20.

Mehrota, R.S. (2001): Plant Pathology. 1st ed. Tata Mc Graw Hill Publishing Company. New York. Pp. $572-584$

Pelczar, M. J. (1993): Microbiology. 5th ed. Mac Graw Hill Publishing Company. Pp. 113 - 115.

Ronald, M. A. (1988): Microbiology. Second Edition. Macmillan Publishing Company. Pp. 100 - 102.

Uzuegbu, J.O. and Emifoniye, A.T. (1984): Post harvest fungal spoilage of some Nigerian fruit and vegetables. Food Journal, 2(1): 153 - 155. 